\title{
Highly Sensitive MEMS Based Capacitive Pressure Sensor Design Using COMSOL Multiphysics \& Its Application in Lubricating System
}

\author{
Krutideepa Bhol \\ Department of Electronics \& Instrumentation Engineering, Institute of Technical Education \& Research, Siksha 'O' Anusandhan University, \\ Bhubaneswar, India
}

\section{Email address:}

research2016mtech@gmail.com

\section{To cite this article:}

Krutideepa Bhol. Highly Sensitive MEMS Based Capacitive Pressure Sensor Design Using COMSOL Multiphysics \& Its Application in Lubricating System. Engineering and Applied Sciences. Vol. 2, No. 4, 2017, pp. 66-71. doi: 10.11648/j.eas.20170204.12

Received: May 28, 2017; Accepted: June 6, 2017; Published: August 11, 2017

\begin{abstract}
Capacitive pressure sensors are making themselves the leader among its market competitors since they consume less power with less temperature sensitivity. This paper includes the design and development possibilities to increase the sensor sensitivity by optimizing the device dimension and including different types of materials. The figure of merits (FOMs) such as displacement, capacitance, electric potential with variation in temperature and pressure are thoroughly analyzed. This paper includes the unique developments, possible challenges with respect to design, modelling, simulation and analysis of MEMS based capacitive pressure sensors. As the range of application level of different sensors is increasing, it is indispensable to review the technological advancement and future possibilities of MEMS capacitive pressure sensors. This paper also focuses on the available reviews of various types of capacitive pressure sensor principles, geometrical design; physics based modelling, parameters analysis to consider, materials that can be used in fabrication process. The 3-D simulation is performed using COMSOL Multiphysics 5.0. During device development all the standards are followed according to the simulation standard set by COMSOL.
\end{abstract}

Keywords: MEMS, Pressuresensor, COMSOL Multiphysics, Sensitivity

\section{Introduction}

In the present era the application of pressure sensor in medicals, aerospace, automobiles, commercial and industrial applications have radically increasing [1-4]. The automotive and health segments are the foremost application sectors, which jointly held more than $45 \%$ share of the worldwide pressure sensor market in 2014. Due to the continuous and progression in the micro scale fabrication expertise, micromachined pressure sensors development have reached the point where low pressure to exceptionally high pressure sensors have developed continously. In the present state of affairs polymer and silicon replaces long-established diaphragm pressure sensor made up of metals. This leads to trim down the material and fabrication cost thereby reduces the product cost/unit. Micromachined pressure sensor is developing importance due to its miniature size, lightweight, integratable to the integrated circuit (IC) fabrication process and smart interface features. It also shows high consistency
[5-12].

Micromachined pressure sensors are tinny editions of their macroscopic competitors [1]. Sensors having diaphragm were developed to measure the effects on deformation on diaphragms due to application of pressure. The shape of the diaphragm is of the form of a square or circle. Silicon and silicon compounds are broadly used in the fabrication of micro pressure sensor [13]. In the present era the application of polymer material has increased due to a variety of advantages like structural stability, more elastic, good electrical and thermal characteristics but having some limitation in high temperature applications. Silicon material has taken the maximum market for pressure sensor fabrication, which can be processed by surface and bulk micromachining. The material properties and fabrication procedure are easy for silicon compared to other available materials. Single crystal or polysilicon diaphragm membrane is used as pressure sensing material for maximum numbers of works. The increase in sensitivities of silicon membrane due 
to reduction in the thickness of the diaphragm or by adding impurities of $\mathrm{P}++$ as explained in [13]. The pressure level is decided according to the thickness of the diaphragm membrane, thinner is suitable for low-pressure application and vice versa. The effect of resistance due to change in temperature is one more crisis with the silicon; it has nonlinear doze off in materials resistance with increase in temperature. In most of the MEMS capacitive pressure sensor, sensor structure is made up of silicon substrate and diaphragm membrane is made up off polysilicon or polymer materials like polyimide, kapton polyimide, SU-8 and Liquid crystal polymers [14].

Capacitive pressure sensors measure the capacitance between two or more conductors in a dielectric medium may be air or water. Real world capacitive pressure sensor design includes moving charges, potential surfaces and partially conducting surfaces [15-32]. For the accurate calculation of field and current to produce a capacitive pressure sensor, Maxwell equation is used. Maxwell built a capacitor with two parallel plates having area A, two partially conducting dielectric of thickness L, dielectric constant $\varepsilon$ and conductivity $\sigma$. The range of application of capacitive pressure sensor is vast but silicon integrated circuit uses the capacitance based cantilever mems to calcullate small displacement [33-58].

\section{Device Design and Simulation}

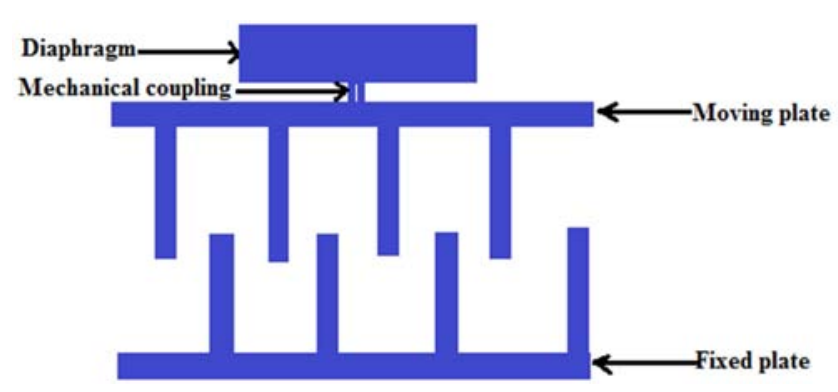

Figure 1. 2-D cross sectional view of comb based capacitive pressure sensor.

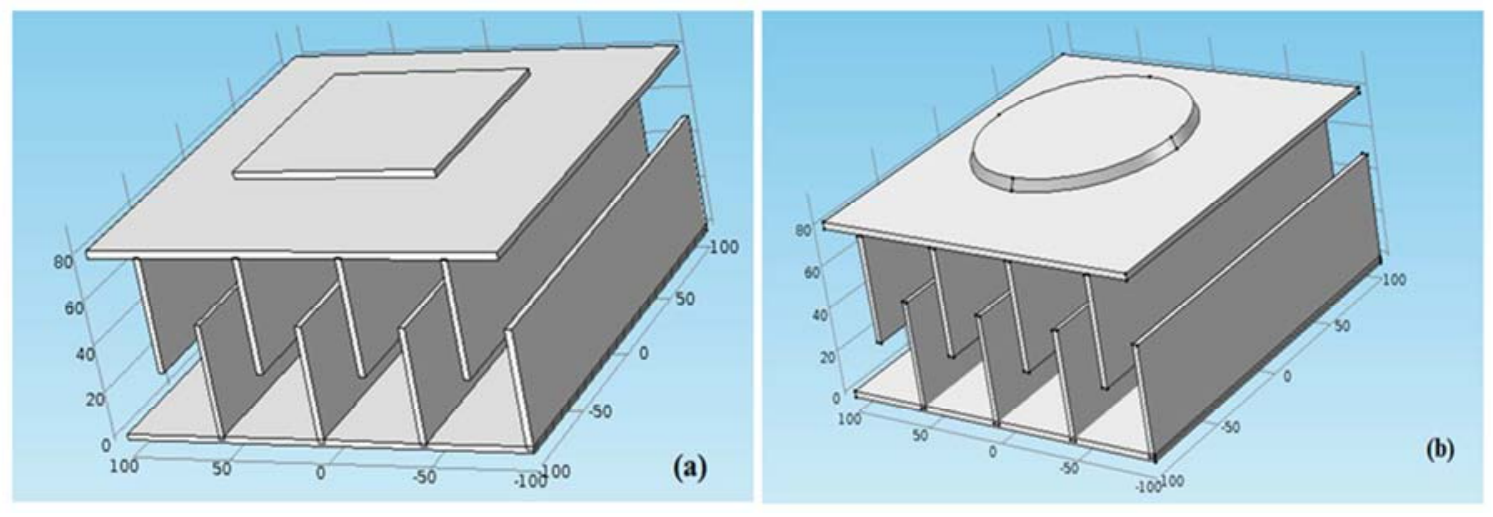

Figure 2. 3-D view of comb based capacitive pressure sensor with (a) square type diaphragm (b) circular type diaphragm.

COMSOL Multiphysics 5.0 is a simulation tool that uses the finite element method for the solution of complex physics problems. This simulation tool includes different equations according to different physics problems into a model. A unique model can use and include various physics conditions to allow the solutions of the problem that are frequently seen in the real world. A number of these mixed circumstances also exist as predefined physics boundaries, such as the piezo-electric devices, which is a mixture of solid mechanics and acoustic piezoelectric.

This is a unique capacitive pressure sensor structure which resembles to a comb having fingers like extensions which measures the capacitance accurately and precisely. Effort is given during design of diaphragm by selecting the thickness and shape of the diaphragm. Thickness of the diaphragm is made thinner in order to calculate the sensitivity correctly. In this design the diaphragm is isolated from the moving plate by a small cylindrical coupling in order to increase the pressure sensitivity. The complete device design and simulation work is carried out using COMSOL 5.0 simulation software [59]. The dimension of the device is made to be $200 \mu \mathrm{m} \times 200 \mu \mathrm{m}$. The thickness of the diaphragm (both square and circular) was made $3 \mu \mathrm{m}, 2 \mu \mathrm{m}$ and $1 \mu \mathrm{m}$ respectively. The capacitance of the device is carried out at a pressure range of 0 to 10 bars. This design is applicable for lubricating system to calculate the oil pressure inside a system. By calculating the pressure and capacitance the status of the lubricating system can be observed.

Between the two moving surfaces a lubrication film is formed which is made up of lubricating oil. If the amount of the lubrication oil varies due to friction or other effects, it directly affects the formation of the thin film by changing the viscosity. When the oil viscosity is not in the required range, the lubrication gets affected. In this design the diaphragm is connected with the movable plate which will calculate the small pressure created in the oil. The bottom and top plates are arranged as a comb like structure which will calculate the capacitance. When pressure is applied on the top plate, it will create a displacement and hence capacitance changes by reducing the separation between the two plates. This capacitance change is measured in terms of voltages. The moving plate of the device is tightly attached at the middle of 
the diaphragm with the help of a mechanical cylindrical coupling. The size of this coupling is small which is about $1 \mu \mathrm{m}$ in radius. The thickness of a diaphragm and thickness of fringes in a comb plate is taken as $2 \mu \mathrm{m}$. The diaphragm is made square and circular for two cases to study the behaviours.

Table 1. Material and Dimension details of the device.

\begin{tabular}{llll}
\hline & $\begin{array}{l}\text { Diaphragm } \\
\text { (Circular) }\end{array}$ & $\begin{array}{l}\text { Diaphragm } \\
\text { (square) }\end{array}$ & Comb plate \\
\hline Material & $\begin{array}{l}\text { Aluminium } \\
(\mathrm{Al})\end{array}$ & $\begin{array}{l}\text { Aluminium } \\
(\mathrm{Al})\end{array}$ & Gold $(\mathrm{Au})$ \\
$\begin{array}{l}\text { Density } \\
\text { Young's }\end{array}$ & $2800 \mathrm{Kg} / \mathrm{m}^{3}$ & $2800 \mathrm{Kg} / \mathrm{m}^{3}$ & $19400 \mathrm{Kg} / \mathrm{m}^{3}$ \\
$\begin{array}{l}\text { Modulus } \\
\text { Poisson's } \\
\text { ratio }\end{array}$ & $180 \mathrm{GPa}$ & $180 \mathrm{GPa}$ & $80 \mathrm{GPa}$ \\
$\begin{array}{l}\text { Device } \\
\text { dimensions }\end{array}$ & $50 \times 2 \mu \mathrm{m}$ & $100 \times 100 \times 2 \mu \mathrm{m}$ & $\begin{array}{l}200 \times 200 \times 2 \mu \mathrm{m}(\text { Plates }) \\
200 \times 50 \times 2 \mu \mathrm{m}(\text { Combs })\end{array}$ \\
\hline
\end{tabular}
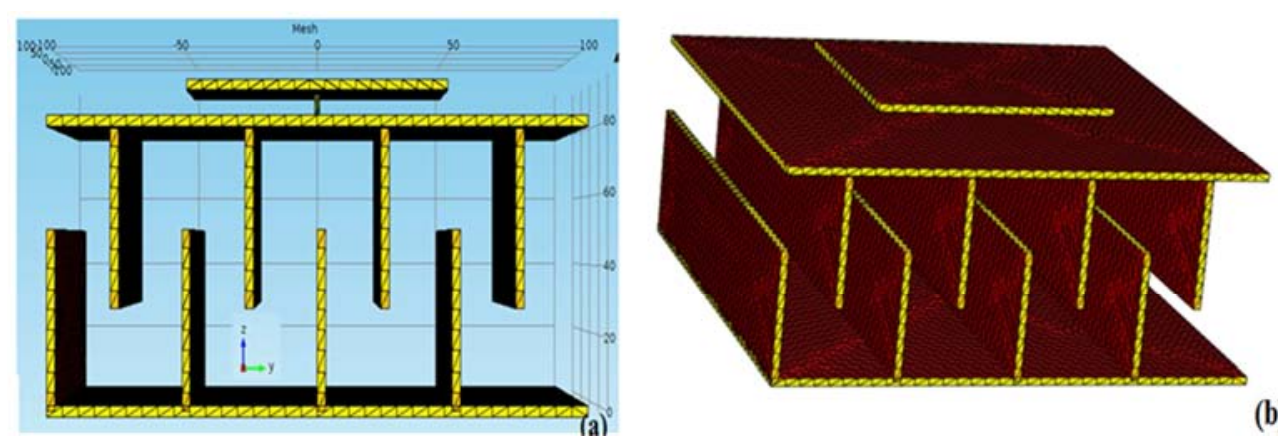

(b)

Figure 3. Cross sectional view of (a) 2-D (b) 3-D Meshing structure of the proposed model.

The meshing structure of the proposed model is given in figure 3 (a) and figure 3 (b) respectively. Figure 3 (a) shows the cross sectional view of the proposed model and figure 3 (b) reflects the three dimensional view of the proposed model with square type diaphragm. The fixed and moving plates with comb like structures are also under meshing in this figure The operation of the device also depends on the meshing structure. This meshing can improve the device performance. This meshing style is different in COMSOL which may be rectangular or triangular.

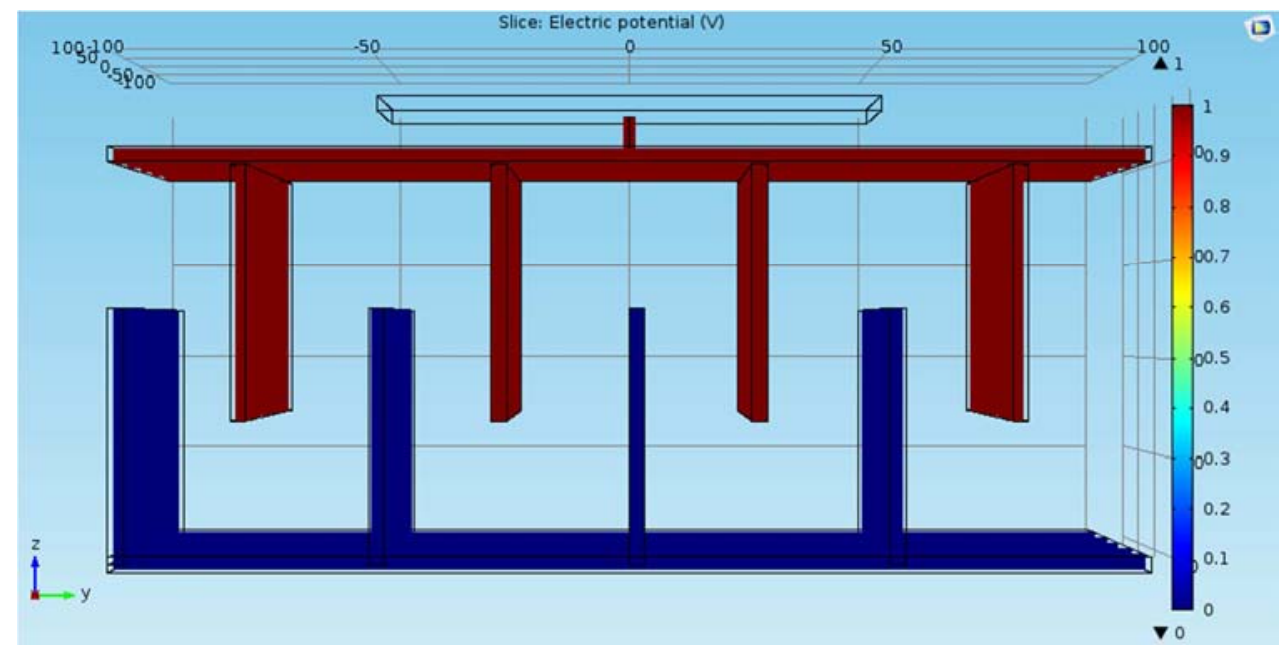

Figure 4. Potential in the fixed and moving plate.

Figure 4. illustrates the potential present in the device. To calculate the lubrication of the oil, the change in capacitance between the two plates is taken into account. Here the moving and the fixed capacitance are in different potentials. The moving plate has a potential of $1 \mathrm{~V}$ where as the fixed plate has a potential of $0 \mathrm{~V}$. Due to the application of pressure on the diaphragm, the moving plate moves towards the fixed plate by changing the potential between 1 and 0 . 

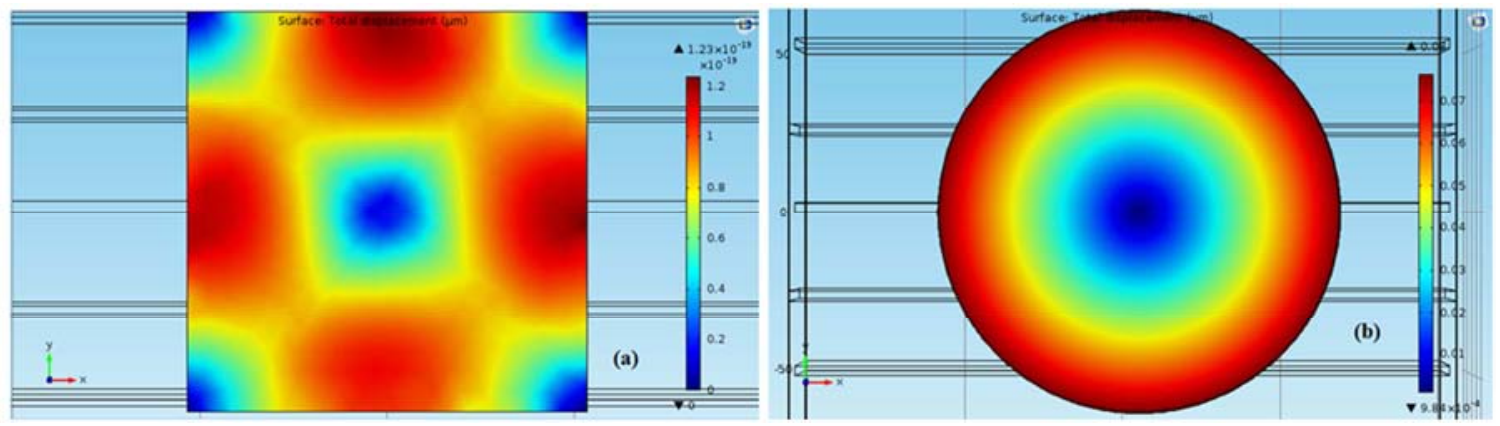

Figure 5. Displacement profile in (a) square membrane (b) Circular membrane.

Figure 5. (a) illustrates the displacement profile of the square membrane when pressure is applied to it. From the figure it can be concluded that the displacement is not uniform if the diaphragm is rectangular rather it is uniformly distributed if it is circular in shape as shown in figure 5. (b). Again Figure 6. explains the variation in capacitance for different materials at different temperatures. From the graph it can be observed that some of the materials show almost same capacitance with variation of temperature. However, gold gives higher capacitance value and noticeable change in capacitance with temperature variation. For this reason we have used gold for our device to make the comb plates and fingers.

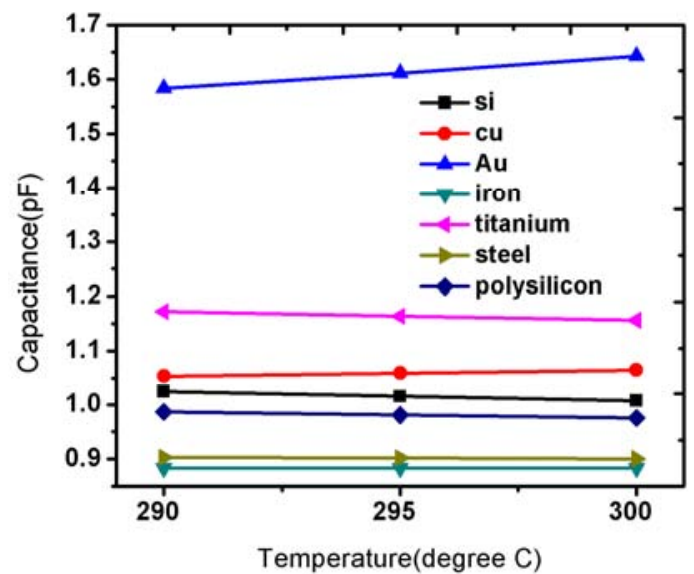

Figure 6. Variation in capacitance at different temperature for different materials.

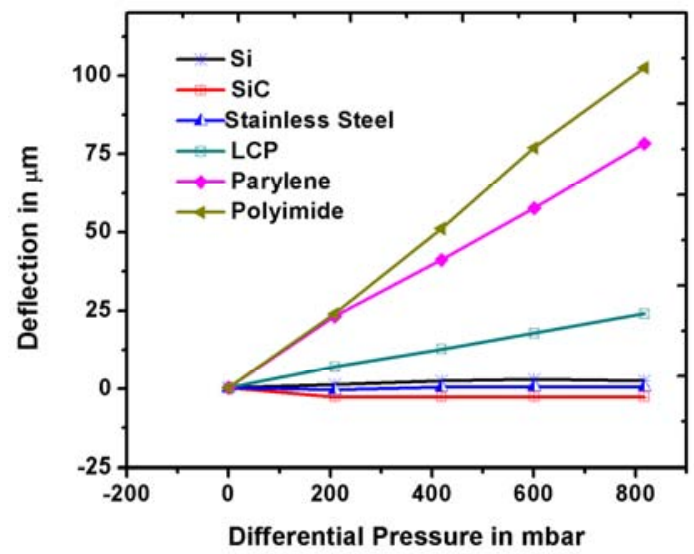

Figure 7. Variation in deflection at different pressure for different materials.
Figure 7. represents the deflection vs. differential pressure for different materials. From the figure it is cleared that polymide material gives higher deflection compared to other materials. Again the sensitivity of the device with different diaphragm thickness is simulated thoroughly. After simulation it is found that with decrease in the thickness of the diaphragm, the sensitivity increases. Similarly with increase in area the sensitivity also increases.

\section{Conclusion}

The introduction of this model gives a noteworthy improvement results in oil state monitoring as the instrument provides a separate diaphragm for pressure sensing and the deflection in the diaphragm creates a stress by moving the movable plate of the capacitor which is helpful in calculating the deflection by change in pressure. The capacitance of the model depends upon the distance of separation between top and bottom plate. With the increase in separation distance between the plates capacitance reduces and increases with increase decrease in plate separation. The diaphragm is made up of aluminium which is coupled with a mechanical cylindrical structure at the centre of the movable plate. Due to the pressure on the diaphragm, the movable plate moves towards the fixed plate by changing the capacitance. The proposed device has the pressure range of 0 to 10 bar.

\section{References}

[1] C. Hierold, B. Clasbrummel, "Low power integrated pressure sensor system for medical applications", Sensors and Actuators (Part A) Physical, vol 73, pp 68-67, 1999.

[2] Y. Zhang, S. Massoud-Ansari, G. Meng, W. Kim, and N. Najafi, A Ultra-Sensitive, High-Vacuum Absolute Capacitive Pressure Sensor, Technical Digest of the 14th IEEE International Conf. on Micro Electro Mechanical Systems(2001), pp 166-169, Interlaken, Switzerland, (2001) 21-25.

[3] Y. Zhang and K. D. Wise, A Barometric Pressure Sensor with Multiple Elements, Digest IEEE Transducers '95 Stockholm, Sweden, (6) (1995).

[4] Y. Zhang and K. D. Wise, An Ultra-Sensitive Capacitive Pressure Sensor with a Bossed Dielectric Diaphragms, Technical Digest of the IEEE Solid-state Sensors and Actuators workshop, Hilton Head Island, SC, (1994). 
[5] Capacitance Based Pressure Transducer Handbook, Understanding, specifying and applying Capacitive Pressure Transducers.

[6] Heerens, Willem Chr., "Application of capacitance techniques in sensor design,” J. Phys. E: Sci. Instrum, vol 19, pp. 897 906, 1986.

[7] Puers, Robert, "Capacitive sensors: when and how to use them," Sensors and Actuators, vol A37-A38, pp. 93-105, 1993.

[8] Sensata Technologies, Pressure Transducers Technical Note 1, Understanding And Specifying Capacitive Pressure Transducers, Mitch Berkson, Original, Dave Field, Update, (2007).

[9] W. H. Ko, Q. Wang, "Touch mode capacitive pressure sensors for industrial applications", in IEEE International Conference, Micro Elec. Mech. Syst. (MEMS) (1997), pp 284-289.

[10] Y. Hezarjaribi, Golestan University, Gorgan, Iran, M. N. Hamidon, A. R. Bahadorimehr University Putra Malaysia, 43400 UPM Serdang, Selangor, Malaysia, S. H. Keshmiri, University of Ferdowsi, Mashhad, Iran Capacitive pressure sensor technology and applications, ICSE (2008) Proceedings. (2008), Johor Bahru, Malaysia.

[11] Toshihiko Omi, Syo Saskai, Fumihiko Sato and Mikio Matsumoto, Central R\&D Laboratory Corporate Research and Development Headquarters, Omron Corporation, Capacitive Pressure Sensor Technology and Applications for Semiconductor Manufacturing Equipment.

[12] A. V. Chavan and K. D. Wise, A Multi-Lead Vacuum-Sealed Capacitive Pressure Sensor, Technical Digest of Solid-state Sensor and Actuator Workshop, Hilton Head, S. C., pp 212$215,1998$.

[13] L. K. Baxter, "Capacitive Sensors," IEEE Press, Piscataway N. J., 1997.

[14] L. Chitra, Y. Ramakrishnan, "Design optimization of piezoresistive Multi MEMS Device for lubricating system", Advances in Natural and Applied sciences, vol 8, pp 76-84, 2014.

[15] A. V. Chavan and K. D. Wise, A Batch-Processed Vacuum Sealed Capacitive Pressure sensor, Digest int. Conf. on SolidState Sensors and Actuators (Transducers'97), Chicago, pp 1449-1452, 1997.

[16] Y. Zhang, R. Howver, B. Gogoi and N. Yazdi, A High Sensitive Ultra Thin MEMS Capacitive Pressure Sensor, Transducers'll, Beijing, China, pp 5-9, 2011.

[17] G. Fragiacomo, A micromachined capacitive pressure sensor with signal conditioning electronics, Master's theis, Universitàdeglistudi di Trieste, Italy, (2008).

[18] M. S. Tabarestani, B. A. Ganji, "Analytical Analysis of Capacitive Pressure Sensor with Clamped Diaphragm", International Journal of Engineering, vol 26, pp 297-302, 2013.

[19] W. H. Ko, "Solid-state capacitive pressure transducers", Sensors and Actuators A: Physical, vol. 10, pp 303-320, 1986.

[20] A. Ravi, R. M. A. Krishna, J. B. Christen, Modeling and Simulation of Dual Application Capacitive MEMS Sensor, Excerpt from the Proceedings of the COMSOL Conference in Boston, 2014.
[21] E. G. Bakhoum and M. H. M. Cheng, "Novel Capacitive Pressure Sensor", Journal of Microelectromechanical Systems, vol 19, pp 345-348, 2010.

[22] B. A. Ganji, M. Shams Nateri, "Modeling of Capacitance and Sensitivity of a MEMS Pressure Sensor with Clamped Square Diaphragm", International Journal of Engineering, vol 26, pp 102-108, 2013.

[23] Y. Hezarjaribi, M. N. Hamidon, A. R. Bahadorimehr, S. H. Keshmiri, Capacitive pressure sensor technology and applications, ICSE (2008) Proceedings.

[24] T. Pedersen, G. Fragiacomo, O. Hansen, and E. VThomsen, "Highly sensitive micromachined capacitive pressure sensor with reduced hysteresis and low parasitic capacitance", Sensors and Actuators A: Physical, vol 154, pp 5-41, 2009.

[25] Zhang, Y., Howver, R., Gogoi, B. and Yazdi, N., A highsensitive ultra-thin mems capacitive pressure sensor, in Solid-State Sensors, Actuators and Microsystems Conference (TRANSDUCERS), $16^{\text {th }}$ International, IEEE., pp 112-115, 2011.

[26] M. M Rahman, and S. Chowdhury, Square diaphragm cmut capacitance calculation using a new deflection shape function, Journal of Sensors, vol 6, pp 234-238, 2011.

[27] C. Zhenhai and R. C. Luo, "Design and implementation of capacitive proximity sensor using microelectromechanical systems technology, Industrial Electronics", IEEE Transactions, vol 45, pp 886-894, 1998.

[28] C. S. Sander, J. W. Knutti, J. D. Meindl, A monolithic capacitive pressure sensor with pulse-period output, IEEE Transactions on Electron Devices, vol 27, pp 927-930, 1980,.

[29] G. Mishra, N. Paras, A. Arora, P. J. George," Simulation of MEMS Capacitive Pressure Sensor Using Comsol Multhysics", International Journal of Applied Engineering Research, vol 7, pp 1-5, 2012.

[30] TamasKarpati, Andrea Edit Pap, Sandor Kulinyi, "Prototype MEMS Capacitive Pressure Sensor Design and Manufacturing", Electrical Engineering and Computer Science, vol 57, pp 3-7, 2013.

[31] P. Eshwaran, S. Malarvizhi, "MEMS Capacitive Pressure sensors: A review on Recent Development and Prospective", IJET, vol 5, 2013.

[32] B. A. Ganji, M. Shams Nateri, "Modeling of Capacitance and Sensitivity of a MEMS Pressure Sensor with Clamped Square Diaphragm", International Journal of Engineering Transaction B: Applications, vol 26, pp 1331-1336, 2013.

[33] Norhayati Soindan Burhanuddin Yeop Majilis, An Analytical Study on Diaphragm Behaviour for Micromachined Capacitive Pressure Sensor, in Proceedings of the IEEE International Conference of Semiconductor Electronics (ICSE), Penang, Malaysia, (2002), 505-510.

[34] AshwinSimha, S. M. Kulkarni, S. Meenatchisundaarm, "An Analytical Method to Determine the Response of a Micro Capacitive Pressure Sensor, Sensors \& Transducers", vol 130, vol 118-126, 2011.

[35] S.-P. Chang, M. G. Allen, "Capacitive pressure sensors with stainless steel diaphragm and substrate", Journal of Micromechanics and Microengineering, vol 14, pp 612-618, 2004. 
[36] H. Jeahyeong and A. M. Shannon, "Smooth Contact Capacitive Pressure Sensors in Touch- and Peeling-Mode Operation", IEEE Sensors Journal, vol 9, pp 199-207, 2009.

[37] Yafan Zhang, Sonbol Massoud-Ansari, Guangqing Meng, Woojin Kim, and Nader Najafian, Ultra-Sensitive, HighVacuum Absolute Capacitive Pressure Sensor, Proceedings of IEEE conference, pp 166-169, (2001).

[38] Vance d A. Browne, George E Kochanek, Capacitance pressure sensor, United States patent 4523474, 1-6, 18 (1985).

[39] W. P. Eaton, Bevan D, James H smith, Capacitance pressure sensor, US patent 6012336, 1-14, 11 (2000).

[40] P. Eswaran, S. Malarvizhi, Modeling of High sensitive MEMS differential Capacitive Pressure Sensor with Polymer diaphragm Membrane, Proceedings of the 9th Nanomechanical sensing workshop NMC 2012, IIT Bombay Mumbai, India, pp 153-154, (2012).

[41] P. Eswaran, S. Malarvizhi, Modeling of MEMS Capacitive Differential Pressure Sensor, Proceedings of (2013) International Conference on Circuits, Power and Computing Technologies [ICCPCT-2013], Noorul Islam University, Kanyakumari, India, pp 699 -702, (2013).

[42] Liwei L, Weijie Y (1998) MEMS pressure sensors for aerospace applications. In: Proceedings of IEEE aerospace conference, 1: 429-436. doi: 10.1109/AERO.1998.686941.

[43] Lee $\mathrm{Y}$ et al "A batch-fabricated silicon capacitive pressuretransducer with low temperature sensitivity", IEEE Trans Electron Dev, vol 29, pp 42-48, 1982.

[44] P. Eswaran, S. Malarvizhi, "MEMS Capacitive Pressure Sensors: A Review on Recent Development and Prospective", International Journal of Engineering and Technology (IJET), vol 5, pp 323-328, 2013.

[45] Zhou M-X et al, "Modeling, design and fabrication of a triple layered capacitive pressure sensor. Sens Actuators", vol 117: pp 71-81, 2005.

[46] Wang Q, Ko WH, "Modeling of touch mode capacitive sensors and diaphragms. Sens Actuators A" vol 75, pp 230 241, 1999.

[47] Zhang $Y$ et al (2011) A high-sensitive ultra thin MEMS capacitive pressure sensor. In: Proceedings of 16th international conference on solid state sensors, actuators and microsystems conference (Transducers), China, pp 112-115.
[48] R. S. Okojie et al (1997) Operation of a (6H)-SiC pressure sensor at $500 \mathrm{C}$. In: Proceedings of international conference on solid-state sensors and actuators, pp 1407-1409.

[49] P. C. Sung et al," Demonstration for integrating capacitive pressure sensors with read-out circuitry on stainless steel substrate". Sens Actuators A vol 116, pp 195-204, 2005.

[50] N. Jithendra et al, "MEMS-capacitive pressure sensor fabricated using printed-circuit-processing techniques", IEEE Sens J vol 6, pp 1374-1375, 2006.

[51] J. Han et al, "Smooth contact capacitive pressure sensors intouch- and peeling-mode operation". IEEE Sens J vol 9, pp 199-209, 2009.

[52] V. Abhijeet et al, "Batch processing of vacuum sealed capacitive pressure sensor. J Microelectromech Syst" vol 10, pp 580-588, 2001.

[53] B. Duck et al Design and simulation of MEMS based combdrive pressure sensor for pediatric postoperative monitoring application. In: 2003 summer bioengineering conference, Florida, pp 1239-1240, 2003.

[54] P. Eswaran, S. Malarvizhi, "Simulation analysis of MEMS based capacitive differential pressure sensor for aircraft application", Adv Mater Res vol 4, pp 4152-4156, 2012a.

[55] P. Eswaran, S. Malarvizhi, "MEMS capacitive pressure sensors: a review on recent development and prospective", Int J Eng Technol, vol 5, pp 2734-2746, 2013a.

[56] P. Eswaran, S. Malarvizhi," Sensitivity analysis on MEMS capacitive differential pressure sensor with bossed diaphragm membrane". In: IEEE international conference on devices, circuits and systems (ICDCS), Karunya University, Coimbatore, India, 15th and 16th March, pp 705-709, 2012d.

[57] V. Mitrakos et al, "Design, Manufacture and Testing of Capacitive Pressure Sensors for Low-Pressure Measurement Ranges”, Micromachines, vol 41, pp 1-10, 2017.

[58] K. B. Balavadab, B. G. Sreeparamatti, V. B. Math, "Design and Simulation of MEMS Capacitive Pressure Sensor Array for Wide Range Pressure Measurement", International Journal of Computer Applications, vol 163, pp 40-46, 2017.

[59] COMSOL Multiphysics 5.0. 